\title{
CUERPO Y CORPORALIDAD DESDE EL VIVENCIAR FEMENINO
}

\author{
María Angélica Montenegro Medina, Claudia Ornstein Letelier y \\ Patricia Angélica Tapia Ilabaca*
}

Resumen: Este artículo revisa las acepciones comunes de los términos "cuerpo" y "corporalidad", las distingue y las sitúa en la vivencia de la imagen corporal femenina actual. Desde este análisis, propone algunas explicaciones en torno del culto al cuerpo, la vigorexia y los trastornos alimentarios. Concluye proponiendo un viraje desde la somatolisis actual a un proceso de integración cuerpo-corporalidad.

Palabras clave: cuerpo, corporalidad, imagen corporal, femenino, género

\section{BODY AND CORPORALITY FROM A FEMININE STANCE}

\begin{abstract}
This paper review the common definitions of body and corporality. These are distinguished and settled in the current feminine corporal image. From this analysis it proposes some explanations in relation to the body worship, the "vigorexia" and the alimentary disorders. This paper concludes proposing a change from the current "somatolysis" to an integrative process of the body and corporality.
\end{abstract}

Key words: body, corporality, corporal image, feminine, gender

\section{CORPO E CORPORALIDADE A PARTIR DA VIVÊNCIA FEMININA}

Resumo: Este artigo revisa os conceitos comuns dos termos "corpo" e "corporalidade", as distingue e as situa na vivência da imagem corporal feminina atual. Desde esta análise, propõe algumas explicações em torno ao culto do corpo, a anorexia e os tanstornos alimentares. Conclui porpondo um olhar a partir da "somatolises" atual a um processo de integração corpo-corporalidade.

Palavras chave: corpo, corporalidade, imagem corporal, feminino, gênero

* Académicos del Departamento de Psiquiatría y Salud Mental, Universidad de Chile. Chile. Correspondencia: angelica_montenegro52@yahoo.com 


\section{Introducción}

En el discurso coloquial hay múltiples referencias a la palabra "cuerpo", toda vez que con ella se quiere representar unidad, totalidad, integridad. Así, por ejemplo, en Derecho Penal o en periodismo policial se habla de "cuerpo del delito" para referirse a un hallazgo irrefutable de una trasgresión; en reuniones de carácter formal suele usarse el término "de cuerpo presente" para señalar la permanencia de alguien ausente; en el ámbito de lo culinario se alude a "tomar y/o tener cuerpo" de algunos preparados o vinos, en señal aparente de equilibrio.

En el hombre normal, el uso de su corporalidad y la certera precisión de sus movimientos parecen estar siempre bajo control voluntario. Ante un prurito, el sujeto dirige su mano hacia la zona de la molestia ejecutando una fricción, en la despereza matinal se extienden ambos brazos, etc. Especial reflexión merece la maternidad. En este evento ontogénico, tan pronto se confirma la espera, la mujer, con frecuencia, deposita ambas manos sobre el vientre como una forma de cobijar al hijo y de explicitar analógicamente el albergue.

Por otra parte, el cuerpo es un claro referente de la expresión emocional, siendo evidente que se expande con la alegría en señal de apertura, de liviandad, y se constriñe con la tristeza, casi como si recayera en el sujeto una pesadez gravitacional. Se podría decir que las emociones "encarnan" en el cuerpo con el consecuente correlato neurológico: taquicardia, sudoración, sequedad de la boca y otros.

\section{La corporalidad en el santo}

Numerosas son las referencias religiosas sobre autoinjurias, flagelaciones, purgas y ayunos a las que se sometían todos quienes, a través del castigo del cuerpo, querían alcanzar la vida eterna. Pareciera que en la vida terrena de quien aspiraba a trascender a una existencia supraterrena, las prácticas en contra de la propia corporalidad constituían una forma válida para alcanzar el Paraíso. El cuerpo aquí es concebido como algo precario, finito, limitado. En la medida en que, voluntariamente, se le haga también doliente, se lo posterga y toma preeminencia la constancia del alma.

Similar actitud ostentaba el héroe épico de la antigüedad. Este exponía temerariamente su corporalidad y, si bien podía perder la vida en los enfrentamientos, era precisamente el sufrimiento corporal el que lo hacía ostentar la categoría heroica.

\section{Cuerpo y corporalidad}

Cuerpo y corporalidad parecen no ser lo mismo. "Cuerpo" se define como una realidad objetiva que, a la manera de un objeto, posee una forma definida. Diversos modelos teóricos señalan que no tiene historia o historicidad (a diferencia de la corporalidad), bastándole sólo la espacialidad.

Esto último permite sostener que el hombre muerto también posee un cuerpo, aunque ya exánime. El cuerpo sufre desgaste según los avances evolutivos del ciclo vital (pesa en la vejez), posee un carácter instrumental, "sirve" para el desplazamiento, la aprehensión, etc., y, curiosamente, tiene una doble pertenencia.

En tanto realidad objetiva pertenece al mundo de las cosas, de los objetos, pero también pertenece al sí mismo. Tenemos nuestro cuerpo, pero a la vez nuestro cuerpo nos tiene. Merleau Ponty señala que la envoltura corporal es a la vez posibilidad y prisión.

La corporalidad, en tanto, hace referencia más bien a la realidad subjetiva, vivenciada o experienciada; por ello está en la intencionalidad de la vida psíquica. La corporalidad 
es historia vital interna, madura hacia la diferenciación; en tanto cada cual tiene su propia historia individual y no se limita al volumen del cuerpo, es capaz de extenderse e incluso tomar posesión de los objetos del espacio. Zutt da gran importancia a la jerarquía en el mundo de la corporalidad, señalando que la vestimenta forma parte de su mundo, es decir, se ha integrado a ella.

Se dice que el proyecto divino sólo se puede realizar a través de la corporalidad, es decir, con la dimensión temporal integrada.

\section{Consideraciones en torno a la imagen corporal}

La palabra imagen proviene del latín "imago", que significa retrato, estatua, representación. El modelo teórico que representa las cosas sin serlas propiamente pertenece al orden de la imagen; por lo tanto, el término imagen corporal pertenece al terreno de lo imaginario. Se presume que cada sujeto tendría, en su imaginario simbólico, una conciencia o imagen de su cuerpo.

Sin embargo, ésta suele ser bastante inasible, dado que el mundo es siempre "sin nosotros", existiendo incluso partes de nuestro cuerpo a las que ni siquiera se puede acceder a través de la imagen especular, cual es la espalda. La representación de una imagen corporal certera es prácticamente imposible; puede llegar a configurarse una imagen aproximada, pero nunca completa. El carácter indefinido, móvil e impreciso de la corporalidad, la no exclusiva adscripción a figura geométrica, propia del cuerpo, dificultan este proceso.

\section{La corporalidad en la actualidad}

La medicina griega clásica establecía una íntima conexión entre "la belleza y la bondad". $\mathrm{Su}$ objetivo era hacer que los hombres fueran bellos y buenos, y no era posible conseguir un fin sin el otro debido al convencimiento de que el cuerpo era el espejo del alma. Así las cosas, el cuerpo alimentado, ejercitado y utilizado en armonía con la naturaleza es bello; en cambio, es feo cuando evita la integración o cuando sucumbe indulgentemente ante el placer. Uno lleva a la armonía y el otro a la destrucción.

La autoimagen es un constructo a partir de la percepción de sí mismo, a lo que se agregan las atribuciones, explícitas o tácitas, de otros respecto de ese sí mismo.

En la actualidad, la atribución en torno a la figura femenina estaría validada sólo desde una mirada esteticista, hedonista, lo que ha redundado en un verdadero culto al cuerpo. Culto que, como muchos otros, está sujeto a rituales; posee nombre propio: vigorexia; decreta una asistencia regular al lugar de culto o templo: gimnasio; su práctica es mediante la repetición de oraciones o mantras: consignas verbales y/o música estereotipada que señalan el compás del ejercicio, y, por último, hace uso de una vestimenta que proporciona identidad con los pares: ropa fitness, equivalente al velo, kipá, etc.

Así las cosas, resulta explicable la emergencia de trastornos de la conducta alimentaria, cuadros que, claramente, afectan en mayor medida a la población femenina. Si bien se presenta sobre todo en la etapa adolescente $-\mathrm{y}$ cada vez más tempranamente-, en las últimas décadas hay una emergencia de estas patologías en la adultez temprana y media.

En términos de identidad de género, la menstruación y el embarazo son dos eventos biológicos que, más que diferenciar, "distinguen" respecto del hombre. La temprana edad de aparición de la anorexia (el 77\% de los casos se inicia antes de los 20 años) trae como consecuencia amenorrea y, no pocas veces, una serie de trastornos en torno a la fertilidad. 
Por otra parte, la apetencia de la mujer por un desarrollo muscular, incluso exagerado, sumado a la eventual interrupción de la menstruación por la práctica de dietas restrictivas, ha ido promoviendo cuerpos más androgénicos $\mathrm{y}$ menos diferenciados de la figura masculina.

La tendencia es preguntarse qué ha ocurrido durante las últimas décadas para que se manifieste este fenómeno. Talvez la mirada que se tiene hoy hacia lo femenino es una mirada fragmentada, en la que no se integra la valoración de "sólo" el cuidado de la prole, en la que se menoscaba el desempeño de la mujer y se la restringía únicamente al quehacer doméstico.

\section{Comentario}

En la sociedad patriarcal existía una clara diferenciación de roles, cabiéndole al hombre uno instrumental, en términos de toma de decisiones y de resolución de problemas, y a la mujer uno expresivo, en cuanto al cuidado de la prole y la expresión y contención emocional.

Pareciera ser que, en la actualidad, hay un retorno al cuerpo en el vivenciar femenino, en tanto pura espacialidad, cayendo en el descrédito la historicidad de ese cuerpo, es decir, su historia vital. El embarazo, la lactancia y otras angustias y pesares propios de los aconteceres biográficos, van dejando, inevitablemente, huellas indelebles. No obstante, la tendencia es al retorno de la imagen juvenil, pretérita, aquella que aún conservaba otra historia de vida.

Pareciera entonces que la vigorexia se trata más de una enfermedad que de un culto, por lo que, en ocasiones, debe ser abordada a través de métodos quirúrgicos para obtener la "sanación".

Creemos imperativo un viraje desde la somatolisis actual a un proceso de integración cuerpo-corporalidad.

\section{Bibliografía}

López-Ibor JJ, López-Ibor Aliño JJ. El cuerpo y la corporalidad. Madrid: Gredos; 1974.

López-Ibor JJ, Ortiz T, López-Ibor MI. Lecciones de Psicología Médica. Barcelona: Masson; 1999.

MINEDUC. Estilos de vida y conducta alimentaria del adolescente. Santiago de Chile: MINEDUC/ Programa MECE MEDIA; 1997.

Ojeda C. El cuerpo biológico (BIOS) en psiquiatría. Revista de Psiquiatría Clínica 1995; 32(1): 57.

Recibido el 21 de abril de 2006.

Aceptado el 04 de mayo de 2006. 